DOI 10.37882/2500-3682.2021.02.08

\title{
КУЛЬТУРА ПАМЯТИ И КУЛЬТУРА ЗАБВЕНИЯ В РАЗВИТИИ ОТЕЧЕСТВЕННОГО ТЕАТРА
}

\section{CULTURE OF REMEMBRANCE AND CULTURE OF OBLIVION IN EVOLUTION OF RUSSIAN THEATRE}

G. Ivinskikh

Summary: The paper deals with problems of theatre during Russia's transitional periods when novelty is, in a certain sense, fetishized. The study covers sharpening of collisions between traditions and avantgarde: traditions come to be billed as routine, traditionalism as social retrogradism. Comparative historical analysis of theatrical life on the cusps of the 19th and 20th and of the 20th and the 21st centuries discovered the potentialities of the transition phenomenon, its algorithm and specific features. Inference is drawn that previous cultural achievements must be developed, not destroyed, as the new is implemented.

Keywords: transitional periods, theatrical life, traditions and avant-garde, remembrance, oblivion.
Ивинских Галина Павловна

К.культурологии, доцент, Пермский государственный институт культуры iwinskih@mail.ru

Аннотация: Статья посвящена проблемам театра в переходные эпохи России, когда происходит своеобразная фетишизация новизны. Исследуется обострение коллизий между традициями и авангардом: традиции начинают приравнивать к рутине, традиционализм - к общественной реакционности. При сравнительно-историческом анализе театральной жизни на рубежах XIX - XX и XX - XXI веков выявлены потенциальные возможности феномена перехода, его алгоритм и специфические черты. Сделан вывод о необходимости при внедрении нового не уничтожать, но развивать предшествующие культурные достижения.

Ключевые слова: переходные эпохи, театральная жизнь, традиции и авангард, память, забвение. амять и забвение как целостные социокультурные явления духовной жизни представляют интерес для культурологического исследования в разных аспектах. В центре внимания автора - трансформации памяти и забвения в сфере театра в переходные эпохи России на рубежах XIX - XX и XX - XXI веков. Компаративистский подход позволяет соотнести и проанализировать рассматриваемые феномены во взаимосвязи с аксиологическим контекстом обозначенных рубежей.

В условиях переходности, наряду с многообразием открывающихся перспектив по обновлению культурной семантики, возрастают и риски, связанные с дестабилизацией, с ослаблением основополагающих функций культуры по интеграции и передаче социокультурного опыта.

Чтобы предотвратить негативные сценарии развития, не утратить чувства преемственности с прошлым, необходима память, «память культуры», опора на исторический опыт. По определению Ю.М. Лотмана, «смыслы в памяти культуры не "хранятся", а растут», прошедшее сохраняется как «пребывающее» [9, с. 674, 675], По мысли ученого, «несмотря на видимое сходство, между забыванием как элементом памяти и средством ее разрушения - глубокая разница. В последнем случае происходит распад культуры как единой коллективной личности, обладающей непрерывностью самосознания и накопления опыта» [там же . 490].
В отечественной истории, к сожалению, немало примеров подобных «распадов». Революционное сознание генерирует пафос отрицания, культ новизны, что, в свою очередь, ведет к радикализации, к осуждению и забвению того, что противоречит доминирующим установкам в обществе, в той или иной сфере деятельности.

На рубеже XIX - XX веков дух модерна, дух обновления, проник во все сферы жизни. В России этот период связывается с понятием «Серебряного века», в котором уникально зафиксирована главная особенность времени - блеск и ускоренный ритм. Культурное пространство стремительно дробилось на школы и направления, на группы и группировки (часто противоположные). На смену символизму (с его идеей преемственности культурных традиций) пришли постсимволистские течения, с ярко выраженным вектором отрицания прошлого, особенно в футуризме. Характерен нигилистический пафос поэмы «Облако в штанах», обозначенный Владимиром Маяковским как «четыре крика четырех частей»: «Долой вашу любовь», «Долой ваше искусство», «Долой ваш строй», «Долой вашу религию».

Особенно зримо изменения представлений о «новых формах» и «старых традициях» обозначились в пространстве сцены. В начале XX века театр вызывал ожесточенные споры. В ходе дискуссий под вопрос ставились не только его традиционные формы, но и самостоятельность театра как вида искусства, сущностное 
значение основных участников театрального процесса - актеров, режиссеров, художников, зрителей.

Скандальный резонанс вызвал сборник - «В спорах о театре» (1914). Скандализировала общество главным образом статья Ю.И. Айхенвальда «Отрицание театра», отрицающая театр не как эмпирическую реальность, а «как эстетический феномен» [5, с. 9-38]. В полемику вступили В.И. Немирович-Данченко, В.Э. Мейерхольд, Ф.Ф. Комиссаржевский, В.Г. Сахновский, М.М. Бонч-Томашевский другие деятели театра (и не только на страницах сборника).

Если обличения Ю.И. Айхенвальда в адрес современного театра большинство оппонентов были готовы принять, то почти никто не согласился с его тезисами о том, что театр «не самостоятелен», «безнадежно зависит от литературы», что он «ложный и незаконный вид искусства». В сборнике, в частности, был напечатан отрывок из книги А.И. Сумбатова-Южина «Театр». По мнению опытнейшего театрального деятеля, «из всех переоценок начала XX века ни одна переоценка не была произведена с такой легкостью, чтобы не сказать развязностью, как переоценка театра» [там же, с. 169].

Конечно, процессы переоценки театра были болезненными, но именно они активизировали его радикальную трансформацию, изменения сценического языка. В ключевом противоборстве между реализмом и условностью на рубеже веков возобладала тенденция «бунта против реальности» (А.В. Луначарский) [16, с. 31]. Характерно письмо М. Горького А.П. Чехову (январь 1900 года) с максималистским отрицанием реализма как отжившей (консервативной) формы: «Право же - настало время нужды в героическом: все хотят возбуждающего, яркого, такого, знаете, чтобы не было похоже на жизнь, а было выше ее, лучше, красивее» [6, с. 113 ].

Как и другие виды искусства, театр той поры все активнее отказывался от жизнеподобия. Особенным нападкам подвергался сценический натурализм. Отрицание тождества театра и жизни, как и стремление преодолеть отчуждение театра от бытия, расширяло пространство для различных концептуальных подходов, для взаимодействия эстетики декаданса и реалистических принципов.

При этом происходило не только противостояние, но и взаимодействие разных принципов. В сценической практике это приводило и к модификации реализма как метода изображения действительности, отнюдь не сводимого лишь к копированию, и к обогащению различных форм «условного театра» сущностным познанием мира и человека. В итоге театр в своих лучших образцах оказался в центре общественного внимания, стал чем-то большим, чем искусство, - жизненно значимым явлением.
После 1917 года новая власть, выдвинув, с одной стороны, демократические лозунги: «Культуру - в массы!», «Искусство принадлежит народу», с другой, - ради блага того же народа уничтожала ценности, якобы чуждые ему. В ходе «культурной революции» под знаменем борьбы с «пережитками царского самодержавия» стало ниспровергаться и предаваться забвению многое из культуры прошлого.

Архиреволюционные силы требовали немедленной реорганизации или вообще упразднения бывших императорских театров и ряда других, вошедших в 1919 году в ассоциацию академических театров. Принадлежащее им имущество предлагалось передать самодеятельным и профессиональным коллективам, созданным после революции.

Если определять основную линию разлома, то по одну сторону «театрального фронта» оказались «старые» театры, ставившие в центр творчества, прежде всего, человеческую личность, по другую находился «левый фронт» искусства, возглавляемый В.Э. Мейерхольдом.

Провозглашенная им программа «Театрального Октября» предполагала подчинение искусства политике и полное обновление сценического искусства на принципах «коллективизма масс». Выступая в декабре 1920 года на Первой всероссийской конференции заведующих подотделами искусств, В.Э. Мейерхольд прямо заявил: «На тех театрах, которые теперь функционируют, надо повесить замок» $[10$, с. 70$]$.

«Вестник театра», печатный орган театрального отдела Наркомпроса, после того, как Мейерхольд возглавил TEO, превратился в рупор идей «Театрального Октября» (редактором «Вестника...» был В.И. Блюм, верный мейерхольдовец). «Лозунги Октября Искусств», опубликованные в «Вестника театра» в феврале 1921 года призывали к борьбе против «гипноза мнимых традиций», «вредной косности» за «установление подлинно марксистского подхода к искусству в области его производственных отношений», за «искание форм для вулканирующего содержания современности» $[8$, с. 1].

Гегемонию в строительстве нового театра активно отстаивал и Пролеткульт. Организация, основанная еще в сентябре 1917 года с целью «культурного вызревания пролетариата», после Октября выросла в массовую разветвленную сеть губернских, городских, районных, фабрично-заводских, подразделений. В отличие от сторонников «Театрального Октября», возлагавших надежды на трансформацию театра усилиями профессиональных мастеров-новаторов (футуристов, кубистов, конструктивистов), пролеткультовцы ориентировались преимущественно на "творчество масс», декларируя отказ от профессиональных драматургов, режиссеров, актеров. 
Согласно пролеткультовским установкам, «Театральный Октябрь могут сделать лишь те классы, которые сделали Октябрь политический» [18, с. 23-24].

Главные идеологи Пролеткульта и его лидер А.А. Богданов, образованнейшие люди, отнюдь не отрицали важности культурного наследия. Но, признавая пролетариат «законным наследником» культуры прошлого, они считали, что пролетарское искусство не должно выходить из своих рамок, - не должно смешиваться с искусством старого мира», чтобы наследство не поработило наследников [3, с. 159].

Подобные теоретические тезисы, спускаясь на «низовые» уровни неизбежно редуцировались, вульгаризировались, приобретали не только искаженный, но и противоположный смысл, который сводился к призывам отправить «искусство прошлого на свалку истории».

К.С. Станиславский, выступая на Всесоюзном совещании по вопросам театра, состоявшемся в мае 1927 года, пытался объяснить, что из политических заказов получается на сцене «агитка», а попытки перетолковать пьесу по-советски ведут к ее разрушению. Аргументируя свою точку зрения, он говорил, что, когда «пробовали в существующие пьесы вложить новую тенденцию, вынимали из пьес душу и вкладывали новую, - из этого ничего не получалось, произведение умирало, как только вынимали из него душу, которая его родила, и так всегда бывает» $[15$, с. 6]. Этой позиции противостояли взгляды тех, кто исходил из идеологических критериев оценки творчества, ориентировался на политические установки.

Современный переходный период, как и рубеж XIX - XX веков, отмечен очередным отрицанием прошлого, обострением коллизий между традицией и авангардом, понимаемом в данном случае в широком смысле, не как определенное направление, а как метаисторическая категория, стремление к новому. За столетний период, разделяющий обозначенные рубежи искусство прошло путь от модерна к постмодерну.

Театр как социокультурный институт и вид искусства (при видовой неизменности), адаптируясь к меняющимся обстоятельствам, испытывает трансформацию практически всех сторон своей деятельности: организационно-экономической, функциональной, творческой.

Если в конце XIX века, в пору становления модерна, эстетические сражения в искусстве происходили между натурализмом, реализмом и модернистскими течениями, что «на театре» выражалось главным образом в борьбе сценического реализма с условностью, то к концу XX века, пожалуй, наибольшие дискуссии в философско-культурологическом и художественном дискурсах вызывают именно постмодернистские тенденции, се- миотическая парадигма, концепции перформативности, постдраматического театра.

В пространстве сцены в роли основного антагониста постмодернистских практик опять выступает реализм. Реализм именно в переходные эпохи начинает подвергаться ожесточенным нападкам. Почему это происходит? Остановимся на двух факторах.

Во-первых, реализм как взгляд на действительность и метод ее художественного выражения в искусстве является воплощенной и яркой традицией с глубокими корнями. Отторжение традиции как таковой, отождествляемой с консервативностью и общественной реакционностью, особенно усиливается в эпохи «бури и натиска», когда происходит активное отрицание устоявшихся норм, канонов. Деформация самого понятия традиции просматривается еще в эпоху Просвещения. Согласно просветительской философии истории, пронизанной духом антитрадиционализма и верой в прогресс, на традиции стали смотреть как на старые обычаи, суеверия, «пережитки», которые следует искоренять. Эта давняя «прогрессистская» установка - «новое лучше старого» и в XXI веке не преодолена.

Во-вторых, в неприятии реализма проявляется терминологическая неопределенность, ведущая к узкому толкованию понятия, к упрощенному и искаженному взгляду на смысл и возможности реалистического подхода в искусстве. В живописи его часто уподобляют умению копировать, в театре приравнивают к жизнеподобию. Реализм в разных модификациях неоднократно провозглашался отжившим, уже само его отрицание считалось признаком авангардности.

Еще на рубеже 1960 - 1970-х годов, при обострившихся поисках сценического языка, в театрах значительно возрос интерес к творческим системам Б. Брехта, В.Э. Мейерхольда, Е.Б. Вахтангова, А.Я. Таирова, М.А. Чехова, которые долгое время замалчивались. Тогда театральная мода явно качнулась в сторону эстетики условного театра,

Появился своего рода «эстетический вопрекизм» по отношению к системе К.С. Станиславского, вызванный многолетним, почти директивным ее внедрением. Хотя Станиславский в этой ситуации неповинен. Учитывая его собственное горькое признание, - «через мои руки прошли сотни учеников, но только нескольких из них я могу назвать своими последователями, понявшими суть того, чему я отдал жизнь» $[14$, с. 375], - становится очевидным, что всеобщая причастность к его системе была иллюзией. По словам режиссера, «некоторые из артистов и учеников приняли мою терминологию без проверки ее содержания или поняли меня головой, но не чувством. Еще хуже то, что это их вполне удовлетворило 
и они стали преподавать якобы по моей "системе". <...> Так называемая "система" принята была понаслышке» (выделено нами. - Г.И.) [13, с. 349-350].

Если еще при жизни автора «система принята была понаслышке», то, что говорить о ее толкованиях, спустя десятилетия. Длительная подмена сущности терминологической оболочкой (в учебном процессе и на практике) привела к выхолащиванию смысловой основы системы. И в таком виде (фактически выхолощенном) она стала вызывать отторжение.

В некий жупел начал превращаться и «психологический театр». В нем, особенно в молодежной творческой среде, видят примитивный, скучный театр. Конечно, недостатки у «психологического театра», сводимого к бытовому, к устаревшей стилистике, были и есть. Но если современный художник будет соотносить себя с образчиками плохого театра, который и раньше был объектом критики, то планка окажется невысока. К сожалению, с отрицанием ложно понятого психологического театра «выплескивается» и собственно психология.

Солидарны с позицией В.В. Иванова, выраженной в первом сборнике «Мнемозины»: «Перестроечная мода на "белые" и "черные" пятна советской истории коснулась и русского театра, не дав сколь-нибудь существенных результатов, более того, налицо урон, связанный с нецеломудренными попытками наскоро переписать прошлое применительно к нынешним вкусам» [7, с. 4].

Примечательна точка зрения на психологический театр, которую высказали в беседе с Ю.М. Барбоем в 2004 году режиссеры разных театральных школ: Александр Галибин, Лев Эренбург, Анатолий Праудин, Сергей Женовач. Все они высказались в том смысле, что «не психологического театра вообще не бывает»:

- Лев Эренбург: «Если театр не психологический, то кому он нужен? Что же он тогда исследует? Как режиссер и как врач я считаю, что психология возникает через физиологию и никак иначе. А обозначаешь ли ты эту физиологию балетом или "один к одному" (скатерть, чашки, чай, сердца разбиваются) - это вопрос языка, жанра, эстетики».

- Анатолий Праудин: «Все социальные, философские вопросы требуют конкретизации, психологической зацепки. А иначе не получится спектакль, будет лекция».

- Сергей Женовач: «Психологический театр - это наивысшее проявление театра как такового. “Психологический театр" и театр - это одно и то же. <..> Психологизм - это свойство театрального искусства. <...> Дело не в жанрах, не в подходах, ни в эстетиках, а дело в самой природе» <...> [1].

Кстати, в этом же ключе высказывался Анатолий Ва- сильев, отвечая на вопрос, чем отличается русская театральная школа от европейской: «Европейская школа не предполагает обучения базовым дисциплинам. Она обучает только прикладным». Базовыми режиссер назвал те дисциплины, структуры, «которые относятся к психологическому театру». И, по его мнению, «всякий, кто херит это, рано или поздно к этому вернется», напомнив, что «последние лекции Мейерхольда о театре очень напоминают те речи, которые мог бы произнести Станиславский» [4, с. 72-73].

В данном контексте примечательна точка зрения известного греческого режиссера Теодороса Терзопулоса, который, начиная с 1993 года, ставит спектакли в России: «Во время перестройки я был в России, <...> я на себе почувствовал все эти разрушительные тенденции. Русские творцы - их настолько поразила западная театральная постмодернистская форма, это их заставило уйти от русской театральной традиции. Они стали все больше обращаться к театру как к продукту, но не к театру как сущности <...>. В русском театре много человечности» [17].

Задача по обновлению сценического языка, искоренению отживших приемов, никогда не может считаться окончательно решенной. Свойства переходности отличают саму природу творческого сознания. Эта природа активизируется при дополнительных внешних импульсах. В неустойчивой ситуации для театра (как целого) важно взаимодействие двух исходных элементов - эксперимент/традиция, - порождающих в диалоге жизнеспособное тройственное единство, которое потенциально содержит многообразие вариантов воплощений.

Абсолютизация любой компоненты запускает деструктивные процессы. Если происходит консервация устаревшей стилистики, система теряет динамику, утрачивает связь со зрителями. Когда театр срывается в хаотическое экспериментирование, новые обретения (если таковые случаются) не успевают укорениться и завоевать публику за рамками фестивалей.

Сопоставление прошлых и нынешних эстетических противостояний демонстрирует засилье бинарных установок («или-или»), по которым лишь одна позиция (своя) трактуется как единственно верная. Исходная агрессивность бинаризма опасна (и не только в искусстве), поскольку способна превращать различия в непреодолимые противоречия.

Если же противоборство разных стилей, направлений, не переходит в крайние, воинствующие формы, это может благотворно воздействовать на развитие эстетической театральной платформы, в сущности, служить движущей силой трансформации. В стабильные фазы происходит взаимодействие новых открытий с предыду- 
щими пластами культуры и приращение смыслов.

Так, Е.Б. Вахтангов, синтезировав условный театр Мейерхольда с мхатовским психологизмом, создал свою школу фантастического реализма с преобладанием игровой стихии, самоиронии. В результате вахтанговская школа, развиваясь, модифицируясь, остается до сих пор живой, а Театр им. Е.Б. Вахтангова - одним из самых востребованных.

Нетерпимость доктринальных установок, не всегда подкрепленная художественными достоинствами, кроме очередного «цитирования» и других постмодернист- ских кодов, порождает в последнее время (в России и на Западе) контртенденции, рассуждения о новом реализме, о новой архаике, романтизме, о неоклассике, о «возвращении автора», о роли канона $[2$, с.10-11; 11; 19$]$.

Как показывают успешные примеры театральной практики, «память культуры», а не забвение является источником развития. Традиции не могут препятствовать современным функциям, если они служат фундаментом и одновременно дополнением последующего поиска. И в силу этого следовать той или иной системе или традиции можно, только развивая ее. Тогда она не будет истощаться, как и сама жизнь.

\section{ЛИТЕРАТУРА}

1. Барбой Ю.М. Психологический театр // Петербургский театральный журнал. - 2004. - № 35. - URL: http://ptzh.theatre.ru/2004/35/ (дата обращения: 19. 12. 2020).

2. Блум Г. Западный канон. Книги и школа всех времен. - М.: НЛ0, 2017. - 672 с.

3. Богданов А.А. [240, С. 159]. 0 пролетарской культуре. 1904-1924 - Л,; М.: Книга, 1924 (на обл. 1925). - 344 с.

4. Васильев А. «А теперь разберемся с базой» // Театр. - 2013. - № 10. - С. 68-75.

5. В спорах о театре. - М.: Книгоиздательство писателей в Москве, 1914. -199 с.

6. Горький М. Письма, телеграммы, надписи // Собр. соч.: в 30 томах. АН СССР. Институт мировой литературы им. А.М. Горького. - М,; Л., 1954. - Т. 28. - 599 c.

7. Иванов В.В. . От составителя // Мнемозина. Документы и факты из истории русского театра XX века. - М.: ГИТИС, 1996. - C. 4-6.

8. Лозунги Октября Искусств // Вестник театра. - 1921. - № 82. - 8 февраля.

9. Лотман Ю.М. Семиосфера. - СПб.: Искусство, 2001. - 704 с.

10. Мейерхольд В.Э. Статьи, письма, речи, беседы: 2 частях. Ч. 2: (1917-1939). - М.: Искусство, 1968. - 643 с.

11. Пелипенко А.А. Постмодернизм в контексте переходных процессов // Искусство в ситуации смены циклов / отв. ред. Н.А. Хренов. - М.: Наука, 2002. C. 383-397.

12. Савчук С. Эпштейн М. Светлой памяти постмодерна посвящается // Художественный журнал. - 2007. - № 64. - URL: http://moscowartmagazine.com/ issue/27/article/472 (дата обращения: 15. 12. 2020).

13. Станиславский К.С. Моя жизнь в искусстве // Собрание сочинений: в 8 томах. Т. 1. - М.: Искусство, 1954. - С. 7-446.

14. Станиславский К.С. Работа актера над собой // Собрание сочинений: в 8 томах. Т. 2.. Ч. 1.- М.: Искусство, 1954. - 424 с.

15. Теасовещание в Наркомпросе // Жизнь искусства. - 1927. - № 19. - С. $2-7$.

16. Театр. Книга о новом театре. - СПб.: Шиповник, 1908. - 289 с.

17. Теодорос Терзопулос о Курентзисе, «Носферату» и философии театра: [интервью] // ИA REGNUM. - 2018. - 27 ноября. - URL: https://regnum.ru/news/ cultura/2526709.html (дата обращения: 23. 12. 2020).

18. Тихонович В. 0 театральных Октябрях // Вестник работников искусств. - 1921. - № 4-5. - С. 21-24.

19. Хренов Н.А. Методологический потенциал культурологии в изучении мирового и отечественного художественного процесса // Textarchive.ru : [сайт]. [Б. м.], 2020. - URL: https://textarchive.ru/c-2511596.html (дата обращения: 20.12.2020). 